\title{
TIPOLOGI RUMAH TANGGA TANI SEBAGAI TITIK MASUK PERTANIAN KONSERVASI: STUDI KASUS DI SEMI-RINGKAI TANZANIA
}

\section{FARM TYPOLOGY AS THE ENTRY POINT OF CONSERVATION AGRICULTURE: CASE STUDY IN SEMI-ARID TANZANIA}

Dina Banjarnahor*

Fakultas Pertanian dan Bisnis, Universitas Kristen Satya WacanaSalatiga

*Corresponding author: dirovaba@yahoo.com.

\section{ABSTRACT}

Crop production in the semi-arid is limited by water shortage and less fertile soil. Conservation agriculture which is based on the principle of minimum tillage, permanent soil cover, and crop diversification has been introduced to Tanzanian local farmers for combating soil degradation and elevating food production. This study sought to explore the feasible entry point for integrating conservation agriculture into the local farms. This goal was achieved by recognizing the local farming system, identifying farm typology, and analyzing the circumstance and needs of different farm types. This study showed that conservation agriculture actually had potentials to reach different farm types. Nonetheless, the practical activities must satisfy the characteristics of each farm. While some farmers perceived hand-hoeing as the most feasible act others were fond of the use of animal-based minimum tillage equipment. Farmers rearing livestock found it difficult to leave crops residue to cover the soil while others were barely constrained. All farmers encountered one similar issue in practicing conservation agriculture: low biomass production to meet the demand of soil cover. Dealing and working with these circumstance and needs of different farm types are then essential in designing the locally appropriate conservation agriculture practices.

Keywords: conservation agriculture, farm typology, semi-arid

\begin{abstract}
ABSTRAK
Produksi pangan di daerah semi-ringkai dibatasi oleh minimnya air dan kesuburan tanah. Pertanian konservasi yang berbasis pada pengolahan tanah yang minimal, penutupan tanah secara permanen, serta diversifikasi tanaman diperkenalkan kepada petani lokal untuk mengatasi degradasi lahan dan meningkatkan produksi tanaman. Studi ini dimaksudkan untuk menggali titik masuk yang tepat dalam mengintegrasikan pertanian konservasi ke dalam pertanian lokal. Tujuan ini dicapai dengan cara mengenali sistem pertanian lokal, mengidentifikasi tipologi rumah tangga tani, dan menganalisis kondisi dan kebutuhan tiap tipe rumah tangga tani. Hasil studi menunjukkan bahwa pada dasarnya pertanian konservasi dapat masuk ke semua tipe petani tetapi tindakan praktisnya berbeda satu dengan yang lain. Ada petani yang lebih sesuai dengan praktek berbasis peralatan manual tetapi banyak juga yang lebih menyukai peralatan pengolahan tanah berbasis tenaga hewan. Petani pemelihara ternak terkendala bila harus meninggalkan sisa tanaman untuk menutupi tanah tetapi petani lain tidak mengalami masalah yang serupa karena tidak membutuhkannya. Satu kendala yang dihadapi seluruh petani adalah rendahnya produksi biomassa tanaman untuk dapat dijadikan bahan penutup tanah. Pertimbangan atas kondisi dan kebutuhan tipe rumah tangga tani yang berbeda ini menjadi esensial untuk merancang tindakan praktis pertanian konservasi yang sesuai konteks lokal.
\end{abstract}

Kata kunci: pertanian konservasi, tipologi rumah tangga tani, semi-ringkai 


\section{PENDAHULUAN}

Pertanian konservasi (PK) dipromosikan di daerah semi-ringkai karena potensinya untuk mengatasi penurunan kualitas tanah dan meningkatkan produksi pertanian. Teknologi ini merupakan pengelolaan agroekosistem dengan menggunakan tiga prinsip ekologis: pengolahan tanah secara minimal, penutupan minimal $30 \%$ permukaan tanah dengan residu tanaman atau vegetasi, dan diversifikasi tanaman secara spasial dan temporal. Implementasi ketiganya diharapkan dapat memberikan keuntungan yang signifikan bagi lahan pertanian (Tabel 1) dan merupakan insentif yang ditawarkan kepada petani di daerah semi-ringkai (Giller et al., 2011).

Tabel 1. Potensi manfaat PK untuk agroekosistem.

\begin{tabular}{ll}
\hline Indikator & Potensi manfaat \\
\hline Karakteristik tanah & Peningkatan C organik tanah, kelembaban dan stabilitas agregat tanah, \\
& serta infiltrasi air (Araya et al., 2012; Thierfelder dan Wall, 2012; Ngwira \\
& et al., 2012a; Ngwira et al., 2012b; Wang et al., 2012) \\
& Pengurangan limpasan air, erosi, dan evaporasi, serta konservasi air yang \\
& lebih baik (Nguema et al., 2013; Wang et al., 2012; Araya et al., 2011) \\
Layanan ekosistem & Pengendalian gulma lebih efektif (Flower et al., 2012), pengurangan risiko \\
& hama dan penyakit, daur ulang hara lebih baik (Kassam et al., 2009) \\
Ekonomi & Jam kerja dan biaya produksi lebih sedikit (Moitzi et al., 2013; Ngwira et \\
& al., 2012a) \\
& Penghematan penggunaan energi dan bahan bakar (Moitzi et al., 2013; \\
& Mohammadi dan Shamabadi, 2012; Faeznia dan Shamabadi, 2012) \\
& Hasil panen lebih tinggi (Thierfelder et al., 2013a, Thierfelder et al., \\
& 2013b; Ngwira et al., 2013; Mupangwa et al., 2012) \\
\hline
\end{tabular}

Salah satu lokasi penyebaran PK di Tanzania (Afrika Timur) adalah Mshewe. Mshewe terletak pada altitude 1000-1500 m di atas permukaan air laut dengan curah hujan tahunan berkisar 600-1250 mm. Suhu minimal dan maksimal dalam setahun berfluktuasi dengan rentang masing-masing antara $5-18^{\circ} \mathrm{C}$ dan $24-28^{\circ} \mathrm{C}$. Tanah bersolum rendah ada di puncak gunung dan lereng sementara tanah yang cukup subur ada di lembah (Tittonell et al., 2012). Evapotranspirasi melebihi curah hujan selama lebih dari sembilan bulan dalam setahun sehingga stres air menjadi salah satu pembatas utama produksi tanaman dan tutupan vegetasi. Tanah yang tidak tertutup vegetasi rentan terhadap erosi tanah. Dalam konteks ini, PK menjadi teknologi yang menjanjikan untuk perbaikan kesehatan tanah dan peningkatan produksi pangan.

Pengenalan PK di tingkat lokal diberikan melalui Sekolah Lapang Petani (SLP). Terdapat empat kelompok tani yang terlibat: kelompok tani desa Mshewe, Muvwa, Njelenje, dan Mapogoro. Pendampingan di lapangan difasilitasi oleh peneliti lokal beserta petugas penyuluh desa melalui demplot eksperimen PK yang ada di tiap kelompok.

Sejauh ini belum ada kajian yang membahas titik masuk (entry point) integrasi PK di dalam sistem pertanian lokal sesuai dengan konteks lokal dan pemahaman petani tentang PK. Penelitian ini dirancang untuk mengenal sistem pertanian lokal, mengidentifikasi tipologi rumah tangga tani yang berbeda, serta menganalisis kondisi aktual dan kebutuhan tiap tipe rumah tangga tani terutama yang relevan dengan konsep pertanian konservasi. Hasil studi dapat menjadi sumber pertimbangan ilmiah untuk perancangan tindakan praktis pertanian konservasi yang lebih mengena untuk rumah tangga tani yang berbeda karakter; tidak hanya di semi-ringkai Afrika tetapi juga di daerah lain dengan persoalan serupa.

\section{BAHAN DAN METODE}

Penelitian dilaksanakan di distrik Mbeya Pedesaan wilayah Mshewe pada 
periode November 2013 - Januari 2014. Data diperoleh dengan cara survei individu, wawancara, dan kunjungan lapangan. Survei individu dilaksanakan terhadap 46 anggota kelompok tani dari jumlah total 85 petani peserta SLP. Terdapat 25 wanita dan 21 pria yang bersedia menjadi narasumber. Mereka berasal dari 43 rumah tangga yang berbeda. Terdapat juga tiga petani bekas anggota kelompok yang dapat ditemui. Wawancara dilakukan dengan informan kunci: pimpinan desa, pimpinan kelompok tani, dan penyuluh.

Informasi yang dikumpulkan adalah karakter wilayah, sistem pertanian lokal, dan karakter rumah tangga tani (RTT). Karakter wilayah dan konteks pertanian lokal dijabarkan secara naratif. Karakter RTT dianalisis secara kuantitatif untuk mengenali tipe RTT yang ada. Untuk analisis tersebut, digunakan 15 variabel RTT yang relevan. Melalui analisis komponen utama nonlinear diperoleh variabel utama yang menjelaskan keragaman RTT. Setelah itu dilaksanakan analisis klaster hirarki untuk mengelompokkan RTT lokal dan menjelaskan sifat RTT berdasarkan variabelnya. Berdasarkan pengelompokan ini, evaluasi titik masuk PK ke dalam pertanian lokal dilakukan berdasarkan kebutuhan dan kendala empirik yang dihadapi petani. Analisis statistik dilakukan dengan menggunakan SPSS 20.

\section{Profil wilayah}

\section{HASIL DAN PEMBAHASAN}

Jumlah rumah tangga di empat desa lokasi penelitian adalah 1.367 dan semua penduduk usia produktif adalah petani. Penduduk yang datang dari luar untuk bekerja di desa (guru atau pegawai pemerintah) juga berusaha tani. Penggunaan lahan didominasi oleh pertanian baik dalam bentuk produksi tanaman dan padang penggembalaan ternak.
Terdapat sedikit variasi kondisi transportasi, pasar, dan aktivitas non pertanian di empat lokasi studi (Tabel 2). Akan tetapi, semua petani di lokasi studi pada dasarnya menghadapi kondisi keterbatasan air yang relatif sama di musim kemarau. Penyebabnya adalah ketiadaan sistem penyimpanan air yang memadai.

\section{Sistem pertanian lokal}

Usaha tani di lokasi studi bersifat skala kecil dengan luas lahan rata-rata 1,52 ha. Selama periode kemarau (Juni-Desember), lokasi studi menjadi sangat kering dan vegetasi sangat minim. Hanya lahan yang dekat mata air yang dapat ditanami namun luasnya terbatas. Lansekap yang berbeda muncul di musim hujan: seluruh lahan dan halaman depan/belakang rumah akan dipergunakan seluruhnya untuk budidaya.

Persiapan lahan dilakukan dengan membakar sisa tanaman dan mengolah tanah sampai pada kedalaman kira-kira 20-30 cm. Tanaman utama adalah jagung dan kacang (Phaseolus vulgaris). Petani membudidayakannya secara monokultur, tumpang sari, dan rotasi. Ada juga yang bertanam padi, sayur, umbi, bunga matahari, tebu, dan kopi.

Kombinasi produksi tanaman dan ternak lazim dijumpai. Ternak mencakup ayam, babi, kambing, dan sapi. Ternak merumput bebas (free-range) di lahan komunal serta berkeliaran di lahan tetangga terutama bila jagung telah selesai dipanen.

Pekerjaan dengan cangkul dikerjakan oleh pria dan wanita. Peralatan dengan tenaga hewan dan alat penyemprot hanya dioperasikan oleh pria. Beberapa petani wanita telah belajar dan menunjukkan minat untuk menggunakan peralatan tersebut tetapi saat studi dilaksanakan sangat tidak lazim untuk melihat wanita mengoperasikannya. 
Tabel 2. Deskripsi karakter wilayah di empat desa lokasi penelitian

\begin{tabular}{|c|c|c|c|c|}
\hline Karakteristik & Mshewe & Muvwa & Njelenje & Mapogoro \\
\hline Luas (ha) & 1427,8 & 2205,1 & 4373,9 & 1657,4 \\
\hline Sumber air & $\begin{array}{l}\text { Mata air, sungai } \\
\text { kecil, beberapa } \\
\text { keran umum. }\end{array}$ & $\begin{array}{l}\text { Sungai kecil, } \\
\text { beberapa keran } \\
\text { umum. }\end{array}$ & $\begin{array}{l}\text { Sungai kecil, } 3 \\
\text { sumur dekat } \\
\text { pemukiman. }\end{array}$ & $\begin{array}{l}\text { Mata air, sungai } \\
\text { kecil, } 10 \text { sumur jauh } \\
\text { dari pusat desa. }\end{array}$ \\
\hline Karakter tanah & \multicolumn{4}{|c|}{$\begin{array}{l}\text { Total } \mathrm{N} 0,06-0,21 \% \text {, total } \mathrm{C} \text { organik } 0,5-2 \% \text {, total Kapasitas Tukar Kation 6-15 } \\
\text { cmol } \mathrm{kg}^{-1} \text {, dan } \mathrm{pH} 5-6 \text {. Njelenje dan Mapogoro adalah area berbatu dengan sisa-sisa } \\
\text { erupsi berupa batuan dan diketahui sebagai sumber fosfat dan phillipsite (Delvaux et } \\
\text { al., 2013). Tanah lapisan atas berwarna gelap ada di bagian timur lokasi studi } \\
\text { (berdekatan dengan hutan lindung). Teksturnya lempung dan liat berdebu. Tanah } \\
\text { lapisan atas berwarna pucat mendominasi bagian barat (lembah). Teksturnya liat } \\
\text { berdebu dan lempung berpasir. Tanah lapisan bawah kuning. }\end{array}$} \\
\hline Lahan ternak & \multicolumn{4}{|c|}{$\begin{array}{l}\text { Lahan keluarga, padang komunal dekat hutan lindung dan lembah, dan lahan } \\
\text { tetangga. Pemagaran tidak lazim. }\end{array}$} \\
\hline Transportasi & $\begin{array}{l}\text { Bajaj, motor, truk, } \\
\text { dan mobil } \\
\text { penumpang } \\
(07: 00-19: 00) .\end{array}$ & $\begin{array}{l}\text { Bajaj, motor, truk, } \\
\text { dan mobil } \\
\text { penumpang } \\
(07: 00-19: 00) .\end{array}$ & $\begin{array}{l}\text { Truk dan mobil } \\
\text { penumpang dari } \\
\text { jam 09:00 s.d. } \\
\text { 17:00. }\end{array}$ & $\begin{array}{l}\text { Truk dari jam 10:00 } \\
\text { s.d. 15:00. }\end{array}$ \\
\hline $\begin{array}{l}\text { Aktivitas non } \\
\text { pertanian }\end{array}$ & $\begin{array}{l}\text { Warung kecil, } \\
\text { pembuatan bir, } \\
\text { tukang bangunan } \\
\text { atau kayu, dan } \\
\text { kerajinan. }\end{array}$ & $\begin{array}{l}\text { Warung kecil, } \\
\text { pembuatan bir, } \\
\text { tukang bangunan } \\
\text { atau kayu, dan } \\
\text { kerajinan. }\end{array}$ & $\begin{array}{l}\text { Warung kecil, } \\
\text { pembuatan bir, dan } \\
\text { konstruksi } \\
\text { bangunan. }\end{array}$ & $\begin{array}{l}\text { Warung kecil, } \\
\text { penjualan kayu } \\
\text { bakar atau arang, } \\
\text { dan pembuatan bir. }\end{array}$ \\
\hline
\end{tabular}

\section{Tipologi rumah tangga tani dan titik masuk} pertanian konservasi

Terdapat empat faktor utama yang menjelaskan tipologi rumah tangga tani yang disurvei. Faktor 1 berhubungan dengan tingkat kemakmuran petani dan produksi tani (variabel luas lahan, jumlah ternak besar, keanekaragaman tanaman, kalender tanam, dan tujuan produksi). Faktor 2 berkaitan positif dengan sumber daya manusia. Faktor 3 dijelaskan oleh keberlanjutan produksi sepanjang tahun karena adanya sumber air. Yang terakhir, sebagian kecil variabilitas dijelaskan oleh faktor keterlibatan petani dalam beternak dan usia kepala rumah tangga. Berdasarkan empat komponen ini maka RTT dikategorikan menjadi empat tipe (Tabel 3).

RTT I (50\% dari total yang disurvei) merupakan petani subsisten dengan sumber daya yang terbatas. Aktivitas tani dilaksanakan hanya selama musim hujan dengan variasi tanaman yang terbatas: jagung, kacang, dan bunga matahari. Banyak yang memiliki pekerjaan sampingan: pembuatan bir, konstruksi, warung, kerajinan, dan pertukangan.
Persentase petani yang menggunakan teknologi pertanian sangat rendah karena kurangnya daya beli. Kendala utama RTT petani adalah ketersediaan kebutuhan pokok: pangan yang cukup, rumah yang baik, bahan dan alat pertanian, kepemilikan tanah dan ternak, serta tenaga kerja. Hampir semua RTT yang dikepalai oleh wanita berada dalam kategori ini; dapat diartikan bahwa rumah tangga tersebut berasosiasi dengan kemiskinan.

Meskipun tidak memiliki ternak, ada petani yang menggunakan peralatan bertenaga hewan untuk mengolah tanah. Hal ini dimungkinkan dengan cara menyewa. Petani dapat meminjam peralatan kelompok tani tetapi harus mengusahakan sendiri tenaga ternaknya. Petani yang membuka jasa penyewaan akan memprioritaskan lahannya terlebih dahulu sehingga petani penyewa alat memiliki risiko keterlambatan tanam.

Praktek PK dengan menggunakan peralatan bertenaga hewan kurang menarik bagi banyak petani dalam kategori ini. 
Tabel 3. Karakterisasi empat tipe rumah tangga tani ${ }^{1)}$

\begin{tabular}{|c|c|c|c|c|}
\hline Variabel & $\begin{array}{l}\text { Tipe I } \\
\mathrm{N}=21^{2)}\end{array}$ & $\begin{array}{l}\text { Tipe II } \\
\mathrm{N}=12\end{array}$ & $\begin{array}{l}\text { Tipe III } \\
\mathrm{N}=4\end{array}$ & $\begin{array}{l}\text { Tipe IV } \\
\mathrm{N}=5\end{array}$ \\
\hline \multicolumn{5}{|l|}{ Kepemilikan lahan } \\
\hline Lahan yang diolah (ha) & $1,2 \pm 0,12$ & $1,5 \pm 0,16$ & $1,8 \pm 0,26$ & $2,1 \pm 0,22$ \\
\hline Lahan beririgasi (ha) & 0,0 & $0,5 \pm 0,09$ & 0,0 & $0,2 \pm 0,16$ \\
\hline \multicolumn{5}{|l|}{ Indikator sosial ekonomi } \\
\hline Jumlah anggota keluarga & $5,4 \pm 0,39$ & $6,0 \pm 0,52$ & $5,5 \pm 1,44$ & $7,0 \pm 1,05$ \\
\hline $\begin{array}{l}\text { Rasio anggota keluarga yang } \\
\text { bekerja di lahan }\end{array}$ & $0,4 \pm 0,06$ & $0,5 \pm 0,07$ & $0,6 \pm 0,16$ & $0,5 \pm 0,08$ \\
\hline $\begin{array}{l}\text { Rasio anggota keluarga yang } \\
\text { bekerja di luar lahan }\end{array}$ & $0,2 \pm 0,05$ & $0,1 \pm 0,04$ & 0,0 & 0,0 \\
\hline Jumlah ternak besar & $0,5 \pm 0,34$ & $2,6 \pm 1,07$ & $2,8 \pm 1,70$ & $3,0 \pm 1,30$ \\
\hline \multicolumn{5}{|l|}{ Kepala rumah tangga } \\
\hline Pria $(\%)$ & 66,7 & 91,7 & 100 & 100 \\
\hline Usia & $47 \pm 2,2$ & $45 \pm 2,9$ & $74 \pm 1,9$ & $48 \pm 4,5$ \\
\hline \multicolumn{5}{|l|}{ Atribut lahan } \\
\hline Jumlah spesies tanaman & $2,9 \pm 0,24$ & $4,1 \pm 0,23$ & $2,5 \pm 0,29$ & $5,0 \pm 0,45$ \\
\hline Pertanian subsisten $(\%)$ & 71,4 & 41,7 & 100 & 40,0 \\
\hline Tani sepanjang tahun (\%) & 0,0 & 100 & 0,0 & 40,0 \\
\hline Luas lahan kopi (ha) & 0,0 & $0,1 \pm 0,02$ & 0,0 & $0,4 \pm 0,04$ \\
\hline \multicolumn{5}{|c|}{ Petani pengguna teknologi pertanian } \\
\hline Pupuk (\%) & 80,9 & 100 & 100 & 100 \\
\hline Herbisida $(\%)$ & 42,9 & 66,7 & 75,0 & 100 \\
\hline Kotoran ternak $(\%)$ & 19,1 & 75,0 & 50,0 & 100 \\
\hline Alat bertenaga hewan $(\%)$ & 52,4 & 66,7 & 100 & 100 \\
\hline
\end{tabular}

1) Variabel dengan nilai kontinyu dituliskan sebagai rerata dan standar deviasi.

2) $N=42$ karena ada satu "outlier" setelah dilakukan analisis.

Penyebab utama adalah keterbatasan akses petani terhadap alat dan ternak. Selain itu, norma lokal belum mengizinkan wanita untuk mengoperasikan peralatan berat. Penggunaan alat berat hanya mungkin apabila di dalam RTT yang dikepalai wanita terdapat anak lelaki usia produktif yang bisa menggarap lahan. Oleh karena itu, tindakan praktek pengolahan lahan sebaiknya tidak berbasis peralatan modern.

Petani umumnya membakar sisa tanaman setelah panen karena tidak memiliki ternak untuk diberi pakan. Hal ini tidak berlaku untuk tanaman kacang; petani memanen seluruh tanaman dan membersihkannya di rumah tanpa mengembalikan residu ke lahan. Praktek meninggalkan residu tanaman di lahan tanpa membakarnya mungkin tidak sulit bagi petani apabila dapat diperkenalkan tanaman pendamping baru pengganti kacang. Secara spesifik, perlu dievaluasi jenis tanaman yang mampu memberikan tutupan yang luas, dapat dimanfaatkan petani, mudah dipanen di lapangan, dan bukan pakan ternak.

RTT II adalah petani muda bermodal dan berorientasi pasar. Petani mampu berproduksi di luar musim karena adanya irigasi kecil. Petani juga memelihara ternak dalam jumlah yang cukup banyak. Terdapat banyak petani pengguna pupuk anorganik di kategori ini tetapi kekurangan pupuk dan peralatan modern tetap merupakan persoalan utama. Tidak ada petani yang mampu memupuk seluruh lahannya. Kotoran hewan merupakan sumber hara tambahan tetapi hanya disebar di lahan terdekat. Kendala utama lainnya adalah minimnya transportasi, akses ke pasar, dan layanan penyuluhan pertanian.

Penggunaan peralatan berbasis tenaga hewan disukai dan diterapkan oleh petani. 
Praktek PK dengan alat manual lebih sulit diterima karena menghabiskan banyak waktu dan energi serta menurunkan status sosial. Fenomena ini serupa dengan keengganan petani di Zambia untuk mencoba praktek PK dengan cangkul karena peralatan manual diasosiasikan dengan kelas sosial yang rendah (Umar et al., 2012). Karenanya, perancangan tindakan pertanian konservasi bagi RTT II harus melibatkan ternak dan peralatan modern apabila ingin dihargai petani.

RTP III yang merupakan kelompok minor $(9,5 \%)$ adalah petani generasi tua dengan modal cukup dan usaha tani yang subsisten. Petani menggunakan pupuk anorganik dan alat pertanian dengan lebih intensif tetapi tetap menganggap minimnya ketersediaan dua komponen tersebut sebagai persoalan utama di lahan. Kendala lain adalah kurangnya tenaga kerja. Dengan tenaga yang terbatas, petani tidak bisa bekerja maksimal dan membutuhkan waktu lebih lama untuk mengolah lahan.

Secara teori, pengolahan tanah secara minimal mengurangi kebutuhan tenaga kerja dan menguntungkan petani kategori ini. Akan tetapi, konteks RTT III akan serupa dengan RTT I: petani terkendala oleh peralatan, ternak, dan operator apabila teknologi yang diperkenalkan berbasis pada peralatan modern. Salah satu praktek yang diterapkan di Afrika Selatan, Zimbabwe, Mozambik adalah penggalian lubang tanam permanen yang hanya perlu dipersiapkan di tahun pertama PK (Ncube et al., 2010). Di Zimbabwe selatan, penggunaan lubang tanam bersamaan dengan aplikasi pupuk $\mathrm{N}$ dosis mikro meningkatkan produksi sampai $78 \%$ di saat curah hujan rendah. Teknik ini dapat menjadi alternatif praktek PK untuk mengurangi beban kerja petani dalam jangka panjang. Percobaan dan pengkajian lebih lanjut tentang manfaatnya bagi RTT I dan III dapat dilakukan peneliti dan petani untuk menjawab persoalan petani yang bersangkutan.

RTT IV adalah petani berorientasi pasar dan bermodal cukup. RTT ini memiliki kesamaan tujuan usaha dan sumber daya dengan RTT II. Hanya saja, petani dari RTT IV tidak memiliki usaha lain dan umumnya hanya bertanam di musim hujan. Petani jarang menyewa buruh dan juga tidak bekerja untuk orang lain. Meskipun tergolong petani bermodal di komunitasnya, terbatasnya pupuk untuk seluruh lahan tetap adalah masalah utama buat petani. Masalah lain adalah minimnya akses ke pasar, layanan penyuluhan, transportasi, dan air terutama untuk tanaman seperti kopi.

Tantangan integrasi PK bagi RTT II dan IV berasal dari persaingan pemanfaatan residu tanaman sebagai pakan ternak dan penutup tanah. Tantangan ini menjadi semakin besar bagi petani RTT IV karena mereka hanya bertanam di musim hujan dan stok pakan akan berkurang drastis di saat kemarau. Penyediaan pakan ternak di musim kering lebih penting bagi petani daripada konservasi tanah.

Di daerah marginal yang produktivitasnya rendah dan sistem pertaniannya bersifat campuran dan komunal, praktek meninggalkan residu tanaman di lahan sulit dilaksanakan (Nyanga, 2012; Umar et al., 2011). Dalam konteks ini, penggunaan tanaman tahunan berpeluang menjadi alternatif karena produksi biomassa berlangsung sepanjang tahun. Integrasi pohon legume ke dalam pertanian konservasi juga direkomendasikan oleh Bayala et al. (2011). Akan tetapi, kajian lanjutan dibutuhkan untuk mengevaluasi efektivitas, manfaat, dan kendala empirik spesies tanaman tahunan tertentu di Mshewe.

\section{Potensi dan riset pertanian konservasi di semi-ringkai}

Berdasarkan analisis tersebut di atas, praktek PK pada dasarnya dapat ditujukan untuk berbagai tipe petani apabila manfaatnya dapat dibuktikan dan pelaksanaannya tidak membebani petani. Peningkatan produksi tercapai hanya apabila ketiga prinsip PK diterapkan secara bersamaan (Corbeels et al., 2014). Dalam kenyataannya, aplikasi residu sebagai penutup tanah merupakan kendala utama yang akan dihadapi oleh semua tipe RTT di Mshewe karena kompetisi penggunaannya untuk tanah dan ternak yang merumput bebas. Penggunaan pupuk secara memadai juga esensial untuk keberhasilan PK karena pupuk yang memadai menopang 
produksi biomassa dan penyediaan residu yang cukup bagi tanah (Corbeels et al., 2014). Seperti yang diakui petani, ketika tanaman jagung tidak dipupuk, hasil panen hanya mencapai 2 karung per ekar (nilai lokal) atau setara dengan 1 ton $\mathrm{ha}^{-1}$. Sementara itu, dengan pemberian pupuk urea dan DAP secara lengkap, hasil tersebut bisa mencapai dengan 5 ton $\mathrm{ha}^{-1}$. Rendahnya tingkat pemupukan lokal membuat produksi biomassa tetap rendah sehingga petani semakin sulit menerapkan seluruh prinsip PK secara bersamaan dan meraih manfaat optimum PK.

Produksi biomassa yang sedikit, dimana terdapat selisih yang jauh antara hasil aktual dan hasil potensial, disebabkan oleh banyak faktor. Tittonell dan Giller (2013) melaporkan bahwa praktek agronomi yang tepatlah yang menjadi kunci untuk menekan selisih hasil panen bahkan ketika pupuk absen. Praktek agronomi ini bisa berupa waktu tanam, jarak tanam, kultivar yang baik, ataupun pengendalian gulma. Hanya ketika praktek agronomi dilaksanakan dengan tepat maka pemupukan akan berdampak nyata.

Di masa yang akan datang, proses integrasi dan perancangan praktek PK harus dilaksanakan secara sinergis dengan evaluasi kemampuan lahan dan praktek agronomi yang dilaksanakan petani. Tujuannya adalah untuk menentukan produksi potensial lokal dan mengetahui faktor pembatas aktual yang menghambat pencapaian potensi tersebut. Petani selama ini menilai kekurangan pupuk sebagai penyebab rendahnya produksi. Akan tetapi, penelitian lanjutan tetap perlu dilakukan untuk menilai efektivitas praktek agronomi tiap RTT. Apabila faktor pembatas ini diketahui maka efektivitas titik masuk dan proposisi tindakan praktis PK yang telah dijabarkan di atas dapat dievaluasi untuk meraih manfaat optimumnya bagi tiap tipe RTT.

\section{SIMPULAN}

Konteks kehidupan dan pertanian lokal di Mshewe secara umum dapat menerima praktek pertanian konservasi apabila tiga prinsip utamanya diselaraskan dengan kebutuhan dan kondisi nyata petani setempat. Potensi ini telah dijabarkan di dalam kajian ini dalam bentuk beberapa alternatif tindakan praktis pertanian konservasi yang spesifik untuk tiap tipe RTT. Persoalan yang juga krusial untuk diatasi adalah kendala umum bersama yang dihadapi petani yaitu rendahnya produksi tanaman sehingga terjadi persaingan penggunaan biomassa tanaman untuk kebutuhan manusia, ternak, dan tanah. Faktor pembatas aktual dalam produksi tanaman lokal perlu diinvestigasi lebih lanjut. Oleh karena itu, bersamaan dengan pengenalan dan penerapan praktek PK yang cocok untuk tiap tipe rumah tangga tani tersebut maka evaluasi kemampuan lahan dan evaluasi praktek agronomi lokal harus dilaksanakan. Tujuannya adalah untuk mengenali faktor pembatas aktual saat ini dan menjembatani keterbatasan tersebut dengan praktek dan persyaratan pelaksanaan seluruh prinsip PK sehingga manfaat optimal PK dapat diraih.

\section{DAFTAR PUSTAKA}

Araya T, WM Cornelis, J Nyssen, B Govaerts, F Getnet, H Bauer, K Amare, D Raes, M Haile, dan J Deckers. 2012. Medium-term effects of conservation agriculture-based cropping systems for sustainable soil and water management and crop productivity in the Ethiopian highlands. Field Crops Research. 132: 5362.

Bayala J, A Kalinganire, Z Tchoundjeu, F Sinclair, dan D Garrity. 2011. Conservation Agriculture with Trees in the West African Sahel - A Review. ICRAF Occasional Paper No. 14, Nairobi.

Corbeels M, RK Sakyi, RF Kühne, A Whitbread. 2014. Meta-analysis of Crop Responses to Conservation Agriculture in Sub-Saharan Africa. CCAFS Report No. 12, Copenhagen.

Faeznia F dan Z Shamabadi. 2012. Evaluation the effect of conservation tillage on rainfed wheat yield and energy efficiency. International Journal of Agriculture and Crop Sciences. 4(22): 1706-1713.

Flower K, N Cordingley, P Ward, dan C Weeks. 2012. Nitrogen, weed management 
and economics with cover crops in conservation agriculture in a Mediterranean climate. Field Crops Research. 132: 63-7

5.Giller KE, M Corbeels, J Nyamangara, B Triomphe, F Affholder, E Scopel, dan P Tittonell. 2011. A research agenda to explore the role of conservation agriculture in African smallholder farming systems. Field Crops Research. 124: 468-472.

Kassam A, T Friedrich, F Shaxson, dan J Pretty. 2009. The spread of conservation agriculture: justification, sustainability and uptake. International Journal of Agricultural Sustainability. 7(4): 292-320.

Mohammadi A dan Z Shamabadi. 2012. Evaluation the effect of conservation tillage on potato yield and energy efficiency. International Journal of Agriculture and Crop Sciences. 4(22): 1778-1785.

Moitzi G, T Szalay, M Schüller, H Wagentristl, K Refenner, H Weingartmann, P Liebhard, J Boxberger, dan A Gronauer. 2013. Effects of tillage systems and ;echanization on work time, fuel and energy consumption for cereal cropping in Austria. Agricultural Engineering International: CIGR Journal. 15(4): 94-101.

Mupangwa W, S Twomlow, dan S Walker. 2012. Reduced tillage, mulching and rotational effects on maize (Zea mays L.), cowpea (Vigna unguiculata (Walp) L.) and sorghum (Sorghum bicolor L. (Moench)) yields under semi-arid conditions. Field Crops Research. 132: 139-148.

Ncube B, E Manzungu, D Love, M Magombeyi, B Gumbo, K Lupankwa. 2010. The Challenge of Integrated Water Resource Management for Improved Rural Livelihoods: Managing Risk, Mitigating Drought and Improving Water Productivity in the Water Scarce Limpopo Basin. CGIAR Challenge Program on Water and Food, Colombo.

Nguema A, G Norton, J Alwang, D Taylor, V Barrera, dan M Bertelsen. 2013. Farmlevel economic impacts of conservation agriculture in Ecuador. Experimental Agriculture. 49(1): 134-147.

Ngwira AR, JB Aune, dan S Mkwinda. 2012a. On-farm evaluation of yield and economic benefit of short term maize legume intercropping systems under conservation agriculture in Malawi. Field Crops Research. 132: 149-1

57.Ngwira AR, C Thierfelder, dan DM Lambert. 2012b. Conservation agriculture systems for Malawian smallholder farmers: Long term effects on crop productivity, profitability and soil quality. Renewable Agriculture and Food Systems. 1: 1-14.

Ngwira AR, C Thierfelder, dan DM Lambert. 2013. Risk and maize-based cropping systems for smallholder Malawi farmers using conservation agriculture technologies. Experimental Agriculture. 121.

Nyanga PH. 2012. Factors influencing adoption and area under conservation agriculture: A mixed methods approach. Sustainable Agriculture Research. 1(2): 27-40.

Thierfelder C dan PC Wall. 2012. Effects of conservation agriculture on soil quality and productivity in contrasting agro-ecological environments of Zimbabwe. Soil Use and Management. 28: 209-220.

Thierfelder C, M Mwila, dan L Rusinamhodzi. 2013a. Conservation agriculture in eastern and southern provinces of Zambia: Long-term effects on soil quality and maize productivity. Soil \& Tillage Research. 126: 246-258.

Thierfelder C, T Mombeyarara, N Mango, dan L Rusinamhodzi. 2013b. Integration of conservation agriculture in smallholder farming systems of southern Africa: Identification of key entry points. International Journal of Agricultural Sustainability. 11(4): 317-330.

Tittonell P dan KE Giller. 2013. When yield gaps are poverty traps: The paradigm of ecological intensification in African smallholder agriculture. Field Crops Research. 143: 76-90.

Tittonell P, E Scopel, N Andrieu, H Posthumus, P Mapfumo, M Corbeels, GE van Halsema, R Lahmar, S Lugandu, J 
Rakotoariso, F Mtambanengwe, B Pound, R Chikowo, K Naudin, B Triomphe, dan S Mkomwa. 2012. Agroecology-based Aggradation-Conservation Agriculture (ABACO): Targeting innovations to combat soil degradation and food insecurity in semi-arid Africa. Field Crops Research. 132: 168-174.

Umar BB, JB Aune, FH Johnsen, dan OI Lungu. 2011. Options for improving smallholder conservation agriculture in Zambia. Journal of Agricultural Science. 3(3): 50-62.

Umar BB, JB Aune, FH Johnsen, dan OI Lungu. 2012. Are smallholder Zambian farmers economists? A dual-analysis of farmers' expenditure in conservation and conventional agriculture systems. Journal of Sustainable Agriculture. 36(8): 908-929.

Wang X, H Wu, K Dai, D Zhang, W Feng, Q Zhao, X Wu, K Jin, D Cai, O Oenema, dan WB Hoogmoed. 2012. Tillage and crop residue effects on rainfed wheat and maize production in northern China. Field Crops Research. 132: 106-116. 